\title{
Lean Innovation of Course Unit Contents
}

\author{
Stelian BRAD \\ Technical University of Cluj-Napoca, Cluj-Napoca, Romania \\ stelian.brad@staff.utcluj.ro \\ Emilia BRAD \\ Technical University of Cluj-Napoca, Cluj-Napoca, Romania \\ emilia.brad@muri.utcluj.ro
}

\begin{abstract}
Designing courses for emerging areas of study is subject to clear challenges. If the envisaged courses are directly paid by the students - as it is the case of this research they are actually the customers whose requirements have to be satisfied. Traditional approaches for collecting student requirements are not feasible for building up very novel topics. For such cases, an approach for course unit design that respects the lean philosophy is introduced in this paper. Lean is about creation of more value for students with fewer resources; or maximizing value while minimizing waste. The approach is based on the paradigm that, in highly dynamic and strong competitive educational markets, top quality courses must be designed from the very early stages. A hypothesis-based process defines the "content-prototype" of the course, which is further tested via web-based surveys that are directed to potential students. Results are statistically interpreted and a refined course content is formulated. The prototype for the most delicate module of the course is elaborated to test the level of delight of potential students (also called the WOW effect). Lessons learned are then considered to design the "promoter-prototype" of the course. A focus group is then used to test if potential students will feel a special experience interacting with the course content (also known as the KANDO effect). The methodology was experimented to design a master course unit on digital entrepreneurship. Empirical researches reveal the viability of the methodology to extract the appropriate topics of a course in emerging areas of study. Researches also show that a well-piloted strategy for course delivery should be in place to achieve the desired market impact.
\end{abstract}

Keywords: course prototyping, lean innovation, digital entrepreneurship

\section{INTRODUCTION}

Various published sources highlight the fact that economic environment faces with rapid changes (Drucker, 2015). The scientific and technological advances, together with other factors like business globalization make a lot of completely new professions to emerge onto the labor market (Durkheim, 2014). Just with an indicative role, an article in Forbes 
from 2012 was entitled "10 Jobs that Didn't Exist 10 Years Ago" (Casserly, 2012). Various foresight studies envisage for the future new needs in the labor market (Frey, 2011; Nusca, 2010; Penserini, 2012). In this context, universities must rapidly adapt, at high quality standards, their educational offers, too. New academic study programs need to be designed and operationalized to face with labor market evolution. Proactive actions to define high quality course units, starting with their 1.0 versions, are also necessary. This is because, in the new socio-economic world, there is not very much space for trial-and-error approaches. Traditional mechanisms of quality assurance in designing and delivery academic course units are based on the premises that stakeholders (e.g. students, employees, faculty staff) know very well the problem and express this by means of specific requirements (Brad, 2014). In the transforming educational environment, where a plenty of means and sources of information and education exist, universities should create "blue ocean" spaces to differentiate their offers with respect to other educational offers on the free markets. A strength of universities, which is still poorly exploited, is the capacity of the academic staff to think visionary and to formulate emerging courses and topics for study. Thus, by analyzing foresight studies and futurologists' opinions, universities can launch emergent study programs, capable to provide qualified graduates in due time. For example, emerging jobs in the years to come, highlighted on the "My_Future" portal, are: alternative vehicle developer, vertical farm engineer, avatar manager, social networking officer, old age wellness manager, etc. (Emerging Occupations, 2015). In this line we also find the job digital business entrepreneur. For such opportunities, universities can adopt courageous actions and initiate visionary study programs.

It is the purpose of this paper to introduce the results from a research project aimed to formulate a reliable methodology for ideation and construction of high quality course units related to emerging topics, where traditional tools of market investigation do not properly work. The methodology is called "lean innovation of course units" and it is the main subject of the subsequent section of the present work. Its experimentation on the emerging topic "e-Entrepreneur", also known as "Digital Entrepreneur", which is going to run from 2016 at the Technical University of Cluj-Napoca in the framework of a private fee-based MSc study program on "e-Businesses" is presented in the section 3. It is shown that, by means of smart approaches, impacting themes can be formulated in this incipient phase of course unit development, even if the target market is not quite familiar with the topic. The challenge is similar to the breakthrough or radical technology-push innovations in the industrial world. Section 4 of the paper is dedicated to conclusions.

\section{LEAN INNOVATION FOR COURSE UNIT DESIGN}

Innovation in this paper is about the whole process of bringing a new course idea to life. It includes the complete phases, from course ideation to course writing and course launching. Lean, in this paper, is seen as the conglomerate of steps and tools considered to avoid any non-value added work in course writing and non-value added topic, information or activity included in the course contents. Both perspectives are in line with the definitions of traditional innovation concept (Dias, 2014) and lean concept (Jasti \& Kodali, 2015), particularized for the case of course unit design. 
The methodological toolbox for lean innovation is introduced in the next paragraphs of this section. It is based on the preventive action paradigm, presented in Figure 1 (original authors' contribution), with the belief that a better planning will diminish later insurmountable or costly risks.

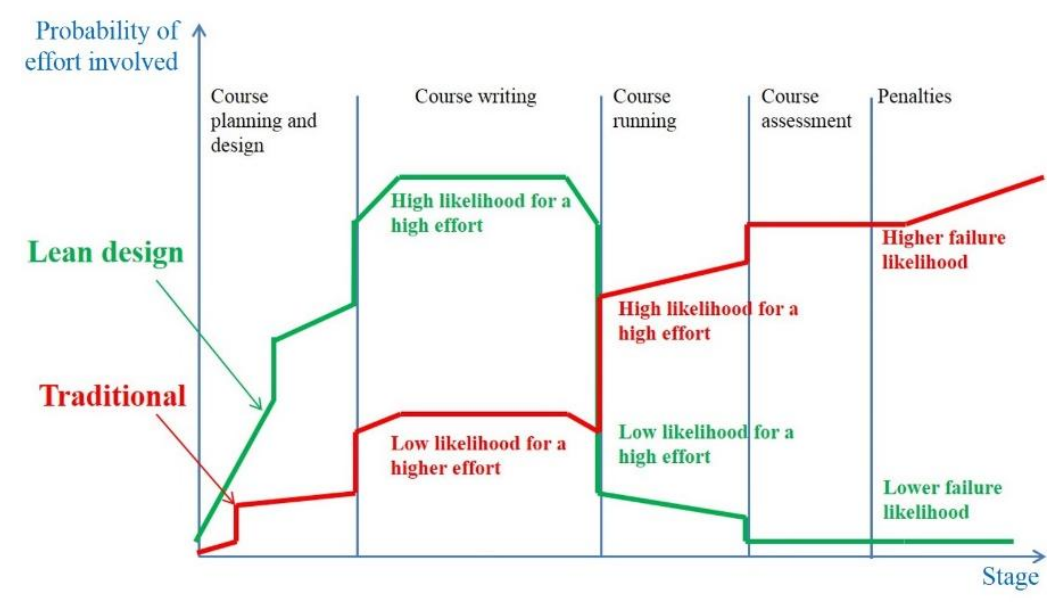

Figure 1: Preventive action strategy vs. traditional strategy.

Step 1: Ideation and impact understanding. Before starting to think around the structure and contents of any module of the course unit, a good understanding of the generic customer (e.g. various "personas" of potential students) is necessary. Academia and industry are not considered customers because they do not pay for the course. To sell something onto the market you need to know the needs and expectations of the buyers. Quality is judged here in restrictive borders - as the perceived value-for-money the buyer is paying. This involves some informal meetings (e.g. in a coffee shop, in an excursion) with people from the target segments to understand their values, priorities, wishes, fears, needs, ways of problem solving, behaviors, etc. Based on these empirical information, various topics that would be of interest for the target market in relation with the course unit are thought. This work has to be supported with information gathered from Internet, magazines and journals. Mind-Mapping, LOTUS, and 9W (e.g. in this order) are powerful tools to support the ideation process. All ideas must be immediately shared and discussed with few "personas" from the target market. Criteria to define the target market include: age (e.g. 23-35), BSc degree profile (e.g. for a course on E-entrepreneurship the BSc profile includes: informatics, computer science, telecommunications, economic informatics, automation, robotics, business, economic engineering), interest on entrepreneurship. In order to see the impact, the "smoke" test is applied. This means, about 10 people from the target market are contacted via email to provide a rapid feedback to your ideas. Ideas must be electronically available, either as attachments to email or in a web page. If $50 \%$ of the contacted persons reply to your request, the conclusion is that the topic might be of real interest. Viable ideas are then selected for further developments. It is 
also necessary to profoundly meditate from the very beginning on how each topic will be useful in practice for the graduates.

Step 2: Testing and refinement of the content prototype. A prototype of the course unit is elaborated at this step. This means, for each module, a summary of the issues included in the course, as well as elements of practical utility are considered. This must be done both for the lecture classes and applicative classes. Information is introduced in a web form for electronic surveying. Tools like Google Forms or Monkey Survey are adequate to support this process. Information about utility (e.g. reduced, medium, and high) of the topics is required. The survey is submitted to a representative sample from the target group. Email addresses are obtained from university or faculty secretariats, alumni offices, study program tutors and student associations. Results from the survey are statistically analyzed and interpreted. Recommendations and conclusions from the survey are sources of inspiration for course content refinement. If the work from the step 1 and step 2 of the methodology is properly done, over $80 \%$ of the respondents in the survey have to appreciate all topics of high utility, otherwise the main streams of the course must be radically reengineered.

Step 3: Prototyping, testing and refinement of the weakest link. For the module with the worst feedback in the survey, two or three representative topics are elaborated into more details. Email opinions from 3 to 5 personas are required. They are selected from the pool of respondents to the survey in step 2; in principles those that responded with high promptness. The "WOW" effect (Munoz, 2013) is tested. "WOW" is an acronym that expresses a very pleasant surprise. It is important to organize an informal meeting with the selected respondents in advance; for example, by inviting them to a coffee in the downtown. Feedback is used to refine the material and to generalize the main lessons learned to the other modules of the course unit.

Step 4: Testing and refinement of the promoter prototype. At this stage, a key topic from each module is elaborated into detail. The occasioned set of topics represents the "promoter prototype" of the course. It is introduced to 10 personas in the target group by organizing a 4-hours workshop. If more than 6 people in the workshop give the maximum appreciation to the content, the chances that the final course to be promoted in the community by word-of-mouth are reasonable high. If this does not happen, content must be revisited, revised and an additional workshop, with other guest participants, has to be very soon organized.

Step 5: Testing and refinement of the prototype for special topics. In order to have a high impact course, every module must include at least one topic that is thought to create a special experience to the audience in the class (the "KANDO" effect). Delighting topics do not necessarily need to be highly elaborated in the prototyping phase. Generation of the "KANDO" effect (Corporate Philosophy, 2014), which determines students to meditate long-time-after to a certain or some key aspects, is not an easy task and this requires creativity and hard work done by the lecturer. "KANDO" is a Japanese word that does not have a precise equivalent in English. "KANDO" is something that inspires the heart and spirit. 
Step 6: Testing and refinement of the delivery strategy. A course can be delivered to students in multiple ways. Modern technologies used in education provide many alternatives to deliver information and knowledge. Strategy should consider the best possible schedule of the face-to-face meetings between students and lecturer. Because each participant in the course has a particular daily program, there is no optimal solution in terms of scheduling face-to-face meetings. Therefore, flexible solutions have to be considered like, for example, the record of the lecture. For a good traceability, the use of multimedia technologies to enhance the course modules with short movies, animations and simulations (where appropriate), is very much welcome. MOOCs-inspired courses (Massive Open Online Courses) and supporting web platforms meet todays' expectations of most students. Value-for-money should be also tested at this stage. A high quality course unit must be self-sustainable, even if it is independently delivered, not necessarily as part of a study program. A course unit is, in principle viable, if a group of 10 students agrees to attend the course and each student is happy to pay $10 \%$ of the overall course costs. This step also includes a systematic work around a cost-effective strategy to educate the wider market about the usefulness and opportunity of the course and around the effective actions to honestly persuade potential students to attend the course. Thus, a delivery strategy requires resources (time, money, technology, skills), which have to be allocated in due time.

Step 7: Guidelines for development. Once the new course is designed, a lot of work is necessary to develop it. This effort involves time, money, documentation work in the library and documentation in the field, interviews with practitioners, ingenuity, and skills for formatting knowledge on digital means (e.g. text, sketches, drawings, graphics, movies, simulations, and animations), as well as other resources (e.g. server, e-learning platform, recording camera, multimedia projector, etc.). All these things need a careful planning. An important aspect at this stage is the cost-benefit analysis over the course life-cycle. Net Present Value (NPV) and Return on Investment (ROI) are useful indicators to limit the level of investment in the development phase of the course unit.

\section{CASE STUDY}

The origin of the lean innovation methodology was actually caused by a real situation with which the authors have confronted in 2014. The university has initiated a private fee-based new master program in e-Activities, with a line of specialization on e-Businesses that is going to start in autumn 2015. A course unit on e-Entrepreneurship was included by the program coordinator in the curricula of this study program and the authors of this paper have been invited to run this course unit starting with autumn 2016. Despite the fact that digital businesses are not necessarily new in the market and the discipline of entrepreneurship is already a consolidated one, the combination of the two fields is seen as an emerging study area because of the specific particularities in the business models and skills necessary for e-entrepreneurs.

The course unit includes $56 \mathrm{~h}$, organized into 14 class modules $(28 \mathrm{~h}), 7$ seminars $(14 \mathrm{~h})$ 
and 7 meetings for project tutoring $(14 \mathrm{~h})$. There are plenty of possibilities to fill this course with information about entrepreneurship and digital businesses, but because of the novelty of the study program in the market, not very many consolidated references exist (e.g. in other universities) to get some clues on the best topics and their weighting within the course structure. Thus, the lean innovation methodology was considered to solve this problem. Because of space constrains, in the following paragraphs of the paper only fragments from the step 2 will be illustrated. The content prototype from step 2 is presented in Table 1. The survey was done using a Google Form worksheet. Invitations were sent to 380 students from several universities in the city that study in the field of informatics, computer science, telecommunications, automation, robotics, electronics, business, and management.

\title{
Table 1: Content prototype (fragments).
}

\begin{abstract}
Module 1: Foundation of entrepreneurship, the entrepreneur, and entrepreneurial profile: understand the key elements of an entrepreneur; entrepreneurship dimensions; major challenges; business life-cycle; entrepreneurial activity; entrepreneurial strategies; entrepreneurial practices; characteristics and qualities of an entrepreneur
\end{abstract}

Module 7: e-technologies for e-entrepreneurship: brief presentation and examples of Web 2.0; Web 3.0; IoT/IoE; IaaS; PaaS; SaaS; big data; cloud computing; augmented reality; data analytics; open source; collaborative innovation

Module 9: Organizational processes in e-enterprises: basic structure of an eorganization; basic organizational functions; roles and attributes; quality management in e-enterprises; process flows; orientation on continuous innovation

Module 10: e-product management for e-businesses: e-product manager attributes; human resource evaluation on innovation; competitive development of e-products; quality planning of e-products; development strategies for e-PSS

...........

Module 14: e-technologies for e-engineering: examples of information systems that support product design and development; key functionalities for collaboration in distributed systems

Seminar 1: The entrepreneurial plan for e-businesses: structure and case study

Seminar 2: Generation of new business ideas in the Net-Economy: methods and exercises

Seminar 5: Business models in e-commerce/e-intermediation/e-service/e-sales: roundtable; case studies collected by students; invited speaker

\begin{tabular}{l}
\hline$\ldots \ldots \ldots . . .$. \\
\hline Project 1: Entrepreneurial plan for e-business $X$ \\
\hline Project 2: Financial plan for e-business $X$ \\
\hline Project 3: Marketing plan for e-business $X$ \\
\hline
\end{tabular}

A number of 90 persons responded to the electronic survey, which falls into a statistical analysis with $\pm 10 \%$ error, at a level of certainty of $90 \%$. Results in the survey show the 
followings:

- Majority of the future students (approx.. 75\%) will appreciate all "step 2"-proposed topics as being of "high utility"

- Respondents that marked some "step 2"-proposed topics with "low utility" or "medium utility" did not recommend alternatives - this meaning they have no clear idea what they would like to see in this course

- Approx. 20\% from the future students would consider $50 \%$ of the "step 2"-proposed topics of "medium utility" and $50 \%$ of "high utility"

- Approx. 5\% of the future students would consider $20 \%$ of the "step 2"-proposed topics of "low utility"

- Approx. 90\% of the future students would appreciate all "step 2"-proposed topics of the seminar of "high utility"

- Approx. 5\% of the future students would consider $30 \%$ of the "step 2"-proposed topics in the seminar of "medium utility"

- Approx. 5\% of the future students would see $40 \%$ of the "step 2"-proposed topics in the seminar of "low utility"

- Approx. 95\% of the future students would see all "step 2"-proposed topics of the project of "high utility"

- Approx. 5\% of the future students would see $30 \%$ of the "step 2"-proposed topics of the project of "medium utility".

Lessons learned from the survey are:

- All topics will be kept, but with some additions to module 14 (i.e. high performance computing technologies to assist e-businesses) and to project 3 (i.e. cases for the marketing plan on e-businesses)

- To increase the impact of module 1 for potential disinterested students on the topic "basics about entrepreneurship" (e.g. because they already know this), an appendix to the course will be included, consisting of a test for self-assessment of personal entrepreneurial qualities

- To increase the impact of module 7 for potential disinterested students on the topic "etechnologies for e-entrepreneurship", real case studies on IoT/IoE will be expanded

- To increase the impact of module 14 for potential disinterested students on the topic "e-technologies for e-engineering", module will be expanded with examples on "etechnologies for product innovation"

- To increase the impact of module 9 for potential disinterested students on the topic related to "organizational processes in e-enterprises", the module will include an appendix with ISO standards on quality management (ISO 9001) and innovation management (ISO/TC 279), as well as with examples of procedures, instructions and records, plus collaborative web platforms.

From the survey, module 1 and module 14 look to be the weakest links of the course. Thus, the step 3 of the lean innovation methodology was concentrated on these two modules. The WOW effect was tested on the following topics: "entrepreneurial practices, characteristics and qualities" (module 1) and "collaboration in distributed systems" (module 14). The contents of these topics have no space for being displayed in this paper. 


\section{CONCLUSIONS}

The main contribution of this paper is the proposal of a lean innovation methodology to design course unit contents for emerging topics in the university private fee-based study programs. Following a "Probe-Test-Evaluate-Learn-Refine" cycle, the methodology is able to unveil the key issues from the very early phases of the course life-cycle, to focus development on WOW and KANDO effects by means of a series of evolving, welltargeted prototypes of the course.

The case study that complements the theory shows that the lean innovation methodology works properly. It allows course developers to know from the early phases of course lifecycle its potential impact and leads the work to converge towards the formulation of a high quality solution.

Some important findings have been also revealed from the experimental research. The most important one is that if the WOW and KANDO effects are achieved on a single topic from each module the high positive impact of that module is ensured. However, to achieve these goals, a lot of creativity and information from real cases is necessary to put in place.

The second important finding is that experts, academics and industry are useful to deliver ideas for course content, but the result should be tested on those stakeholders that are going to pay the course - the potential students.

The third finding is that respondents are capable to express what they want and do not want once they have in front of them a proposal. This means a starting prototype must be in place - even if it is based on hypotheses - such as respondents can analyze their needs with respect to something and can provide feedbacks that are helpful for refining the content.

\section{REFERENCES}

Brad, S. (2014). Design for Quality of ICT-Aided Engineering Course Units. International Journal of Quality Assurance in Engineering and Technology Education, 3(1), 52-80.

Casserly, M. (2012). 10 Jobs that Didn't Exist 10 Years Ago. Forbes. Retrieved June 12, 2015 from http://www.forbes.com/sites/meghancasserly/2012/05/11/10-jobs-that-didntexist-10-years-ago/

Dias, M. F. P., Pedrozo, E. A. \& da Silva, T. N. (2014). The Innovation Process as a Complex Structure with Multilevel Rules. Journal of Evolutionary Economics, 24(5), 1067-1084.

Drucker, P. (2015). Innovation and Entrepreneurship. New York, USA: Routledge.

Durkheim, E. (2014). A Division of Labor in Society. New York, USA: Free Press.

Frey, T. (2011). 55 Jobs of the Future. Retrieved May 12, 2015 from http://www. futuristspeaker.com/2011/11/55-jobs-of-the-future/ 
Jasti, N. V. K. \& Kodali, R. (2015). Lean Production: Literature Review and Trends. International Journal of Production Research, 53(3), 867-885.

Munoz, J. (2013). How to Create a WOW Customer Experience. Retrieved April 10, 2015 from http://deliveringhappiness.com/create-wow-customer-experience/

Nusca, A. (2010). Top 20 Most Popular Future Jobs for 2030. Retrieved February 15, 2015 from http://www.zdnet.com/article/top-20-most-popular-future-jobs-of-2030-verticalfarmer-limb-maker-waste-data-handler-narrowcaster/

Penserini, L. (2012). The New Professions for Europe 2020. Paper presented at the meeting of International Week and Erasmus Day. University of Camerino, Italy.

***. (2014). Corporate Philosophy. Retrieved January 15, 2015 from http://global. yamaha-motor.com/about/philosophy/

***. (2015). Emerging Occupations. Retrieved May 20, 2015 from http://my future.edu.au/explore-careers/occupation-showcase/emerging-occupations 